\title{
Bariatric surgery in hypothalamic obesity
}

\author{
Nathan C. Bingham ', Susan R. Rose ${ }^{1}$ and Thomas H. Inge ${ }^{2 *}$ \\ 1 Division of Endocrinology, Cincinnati Children's Hospital Medical Center, University of Cincinnati College of Medicine, Cincinnati, OH, USA \\ 2 Division of Pediatric General and Thoracic Surgery, Cincinnati Children's Hospital Medical Center, University of Cincinnati College of Medicine, Cincinnati, OH, USA
}

\section{Edited by:}

Hermann L. Mueller, Klinikum

Oldenburg GmbH, Germany

\section{Reviewed by:}

Roberto Salvatori, Johns Hospital University, USA

Fredric Wondisford, Johns Hopkins University School of Medicine, USA Christian Roth, University of Washington School of Medicine, USA Martin Wabitsch, University of UIm, Germany

\section{*Correspondence:}

Thomas H. Inge, Cincinnati Children's Hospital Medical Center, 3333 Burnet Avenue, Cincinnati, OH 45229, USA. e-mail: thomas.inge@cchmc.org
Craniopharyngiomas (CP) are epithelial neoplasms generally found in the area of the pituitary and hypothalamus. Despite benign histology, these tumors and/or their treatment often result in significant, debilitating disorders of endocrine, neurological, behavioral, and metabolic systems. Severe obesity is observed in a high percentage of patients with $\mathrm{CP}$ resulting in significant comorbidities and negatively impacting quality of life. Obesity occurs as a result of hypothalamic damage and disruption of normal homeostatic mechanisms regulating energy balance. Such pathological weight gain, termed hypothalamic obesity (HyOb), is often severe and refractory to therapy. Unfortunately, neither lifestyle intervention nor pharmacotherapy has proven effective in the treatment of HyOb. Given the limited choices and poor results of these treatments, several groups have examined bariatric surgery as a treatment alternative for patients with $\mathrm{CP}-\mathrm{HyOb}$. While a large body of evidence exists supporting the use of bariatric surgery in the treatment of exogenous obesity and its comorbidities, its role in the treatment of $\mathrm{HyOb}$ has yet to be defined. To date, the existing literature on bariatric surgery in $\mathrm{CP}-\mathrm{HyOb}$ is largely limited to case reports and series with short term follow-up. Here we review the current reports on the use of bariatric surgery in the treatment of $\mathrm{CP}-\mathrm{HyOb}$. We also compare these results to those reported for other populations of $\mathrm{HyOb}$, including Prader-Willi Syndrome, Bardet-Biedl syndrome, and hypothalamic melanocortin signaling defects. While initial reports of bariatric surgery in $\mathrm{CP}-\mathrm{HyOb}$ are promising, their limited scope makes it difficult to draw any substantial conclusions as to the long term safety and efficacy of bariatric surgery in CP-HyOb. There continues to be a need for more robust, controlled, prospective studies with long term follow-up in order to better define the role of bariatric surgery in the treatment of HyOb.

Keywords: craniopharyngioma, bariatric surgery, gastric bypass, hypothalamic obesity

\section{INTRODUCTION}

Craniopharyngiomas $(\mathrm{CP})$ are generally benign, slow-growing tumors that are thought to arise from rests of embryonic cells residing within the remnants of the craniopharyngeal duct or Rathke's pouch (Abeloff, 2008). Thus, tumors may originate from anywhere along the path of the craniopharyngeal duct, from nasopharynx to tuber cinereum, although most are located in the sellar/parasellar region (Harwood-Nash, 1994; Karavitaki et al., 2005). Although histologically benign, these tumors are often locally aggressive with invasion of adjacent tissues and structures. While mortality is generally low, morbidity as a result of tumor mass effect and/or therapy (resection \pm radiotherapy) is substantial and nearly universal (Mortini et al., 2011; Winkfield et al., 2011).

Because of the close proximity to the visual nerve tracts, hypothalamus, pituitary, and ventricular system, CPs predispose patients to a number of adverse endocrine, metabolic, psychologic, and neurologic sequelae. As a primary result of the tumor, the majority of patients present with one or more hypothalamic-pituitary deficits including growth hormone (GH; $\sim 75 \%$ ), gonadotropins $(\sim 60 \%)$, adrenocorticotropic hormone (ACTH; $\sim 30 \%$ ), thyroid-stimulating hormone (TSH; 25\%), and/or antidiuretic hormone (ADH; 20\%; Karavitaki et al., 2006; Muller, 2008). In addition, approximately one-third can develop new or additional endocrinopathies following surgical resection.

\section{HYPOTHALAMIC OBESITY}

In addition to pituitary hormone deficiencies, hypothalamic involvement has been shown to result in severe metabolic disturbances and weight gain (Muller et al., 2001; Srinivasan et al., 2004). While a minority (15-20\%) of CP patients complain of weight gain as a presenting symptom, more than $50 \%$ develop significant obesity following surgical resection (Muller et al., 2004; Ahmet et al., 2006). This number may be as high as $90 \%$ in those with demonstrable hypothalamic damage, whether from direct tumor infiltration or as a result of surgical and/or radiation therapy (de Vile et al., 1996; Muller et al., 2004). Such pathological weight gain, termed hypothalamic obesity (HyOb), is often severe, refractory to therapy, and has a significant negative impact on the quality of life for patients with CP (Muller et al., 2005; Eyal et al., 2006; Inge et al., 2007).

Over the last 75 years, experience with animal and human models has shown the basal medial hypothalamus to be a key center of metabolic regulation by the central nervous system (CNS; Hetherington and Ranson, 1940; Sorva, 1988). The hypothalamus receives and integrates a variety of afferent signals communicating the metabolic state of the organism and adjusts autonomic outputs with the ideal physiologic outcome of maintaining adequate energy stores. The afferent arm of the homeostatic loop consists of hormones, such as leptin, insulin, and peptide YY, 
that target receptor fields within hypothalamic nuclei to convey information on meal size, nutrient composition, and adipose tissue stores. In addition, neurons within the hypothalamus directly sense and respond to nutrients, such as free fatty acids, glucose, and amino acids. Within the hypothalamus, neuropeptides such as neuropeptide Y (NPY), agouti-related protein (AgRP), and alphamelanocyte stimulating hormone $(\alpha-\mathrm{MSH})$, integrate and convey this information to other brain centers responsible for controlling appetite/satiety, thermogenic, and motor effectors (Schwartz et al., 2000).

A number of monogenetic obesity syndromes have now been shown to involve mutations in such regulatory hypothalamic pathways (Clement et al., 1998; Lubrano-Berthelier et al., 2006; Savastano et al., 2009; Hochberg and Hochberg, 2010). In addition, several complex genetic syndromes, including Prader-Willi (PWS) and Bardet-Biedl syndromes (BBS), are associated with obesity, presumably from hypothalamic dysfunction. PWS results from the loss of paternally imprinted genes on chromosome 15q11-15 and is characterized by an array of multisystemic defects including neonatal hypotonia, short stature, hypogonadism, behavioral and psychiatric phenotypes, aggressive food-seeking behavior, hyperphagia, and obesity (Goldstone et al., 2008). PWS patients have significantly elevated levels of the orexigenic hormone ghrelin, a finding not observed in other causes of HyOb (Cummings et al., 2002a; DelParigi et al., 2002). Interestingly, even young, underweight patients with PWS exhibit higher BMI-adjusted body fat and serum leptin levels, suggesting some intrinsic leptin resistance in PWS (Eiholzer et al., 1999). BBS is a multisystemic disorder characterized by retinal degeneration, hypogonadism, polydactyly, renal dysfunction, mental retardation, and obesity resulting from defects in ciliary function. Hypothalamic dysfunction in these patients is suggested by the study of mice harboring mutations in BBS genes. BBS mutants have been shown to be hyperleptinemic and have defective hypothalamic leptin signaling (Seo et al., 2009; Guo and Rahmouni, 2011).

Thus, damage to, or dysfunction of the hypothalamus results in an inability of the CNS to receive proper feedback. Patients, thus, inappropriately sense a perpetual state of starvation. To correct the perceived negative energy balance, efferent outputs are adjusted to promote caloric intake and decreased caloric expenditure. Decreased sympathetic activation of $\beta_{2^{-}}, \beta_{3^{-}}$, and $\alpha_{2-}$ adrenergic receptors reduce skeletal muscle thermogenesis, reduce adipose tissue lipolysis, and promote pancreatic insulin secretion, respectively. Conversely, increased parasympathetic output through the vagus nerve slows the heart rate reducing myocardial oxygen consumption, promotes gastrointestinal peristalsis and substrate absorption, and accentuates post-prandial insulin secretion (Lustig, 2008). The net result of this reduced sympathetic/parasympathetic ratio is significantly decreased energy expenditure with partitioning of calories away from energy consuming tissue such as muscle and toward energy storage depots such as adipose tissue.

Accumulating evidence supports the hypothesis that CP and its therapies often result in dysfunction of the normal homeostatic mechanisms regulating appetite and metabolism. Leptin, a potent anorexigenic peptide secreted by adipocytes, has been found to be elevated in CP patients compared to obese controls suggesting a defect in the normal feedback inhibition of appetite. In addition, some CP patients have a blunted post-meal increase in the anorexigenic hormone peptide YY. Hypersecretion of the orexigenic gastric hormone ghrelin is thought to contribute to hyperphagia and obesity in PWS, although this does not seem to be the case in $\mathrm{CP}$ where pre-meal ghrelin levels are lower than weight-matched controls. Recently, however, Roth et al. found that there may be a reduction in the expected magnitude of post-meal suppression of ghrelin levels in CP patients (Roth et al., 1998, 2011; Holmer et al., 2010).

While there are reports of hyperphagia and obsessive foodseeking behavior after CP (Skorzewska et al., 1989), a number of studies have now shown that caloric expenditure, and not caloric intake, may be the largest contributor to post-CP-HyOb (CP$\mathrm{HyOb}$ ). Adults and children with $\mathrm{CP}-\mathrm{HyOb}$ have been found to have impaired sympathoadrenal activation in response to hypoglycemia, although this defect does not appear to always correlate with development of obesity or hypothalamic involvement (Schofl et al., 2002; Coutant et al., 2003). In a larger study, $\mathrm{CP}-\mathrm{HyOb}$ patients were found to have lower levels of urine catecholamines than BMI-matched controls (Roth et al., 2007), suggesting decreased sympathetic tone.

As sympathetic tone correlates with spontaneous motor activity, one might also expect lower levels of physical activity in $\mathrm{CP}$ patients. Indeed, CP patients consistently report reduced physical activity, even when compared to controls with similar BMI (Roth et al., 2007). Using accelerometric data, Harz et al. demonstrated that obese CP patients had decreased spontaneous motor activity compared with age and BMI-matched controls. Using food diaries, this same group showed that caloric intake was lower in CP patients with hypothalamic damage, despite a significantly increased BMI (Harz et al., 2003). These findings were substantiated by a recent study by Holmer et al. in 42 adult patients with childhood CP, where CP patients were found to have a significantly reduced basal metabolic rate when adjusted for body weight, than age and sex matched controls. Analysis of energy intake showed lower caloric consumption in $\mathrm{CP}$ patients which was attributed to cognitive restraint in eating (Holmer et al., 2010). Aside from reduced sympathetic drive, the roadblocks to physical activity are substantial and likely contribute to reduced energy expenditure and risk for obesity. Neurological and visual deficits may contribute to limited movement in some CP patients. In addition, there is evidence that $\mathrm{CP}$ patients have disordered sleep patterns secondary to decreased melatonin and/or secondary narcolepsy causing daytime sleepiness (Muller et al., 2002, 2006). Obstructive sleep apnea (OSA) in these patients also likely contributes to poor sleep hygiene.

Under- or overtreatment of hormonal deficiencies may also contribute to poor metabolic parameters and weight gain in $\mathrm{CP}$ patients. Glucocorticoid excess is a known cause of significant weight gain, impaired glucose metabolism, sleep disturbance, and defects in bone metabolism and growth (Debono et al., 2009). Most significantly, excess glucocorticoid dosing has been associated with increased mortality from cardiovascular disease. In a large cohort of Scandinavian patients with hypopituitarism, Filipsson et al. (2006) showed that those receiving higher doses of glucocorticoid replacement had significantly higher waist circumference, total cholesterol, serum triglycerides, and HbA1c. Daily 
cortisol production rates range from 6 to $8 \mathrm{mg} / \mathrm{m}^{2} /$ day, much less than previous estimates (Linder et al., 1990; Esteban et al., 1991; Kerrigan et al., 1993; Brandon et al., 1999). Thus, the classic adult dosing of $20 \mathrm{mg}$ of hydrocortisone in the A.M. and $10 \mathrm{mg}$ in the P.M., is likely an excessive dose. Unfortunately, no objective test of adequate glucocorticoid replacement has been shown to be sufficiently consistent to aid in dosing management and patients must be followed closely for clinical signs of glucocorticoid deficiency or excess.

Hypothyroidism also results in poor metabolic health and is associated with fatigue, low basal metabolic rate, increased BMI, and increased cholesterol and triglyceride levels (Kronenberg and Williams, 2008) and adequate replacement has beneficial effects on these parameters (Slawik et al., 2007). Management of thyroid hormone replacement is made more challenging in CP patients by the absence of the patient's own endogenous "thyrostat" as TSH levels cannot be used to judge adequacy of treatment. The significance of this handicap is highlighted in a recent study comparing free T4 (fT4) levels in TSH deficient patients to those in primary hypothyroid patients where TSH levels are used to guide therapy. Nearly $40 \%$ of TSH deficient patients were found to have fT4 levels below the 20th centile range compared to $13.4 \%$ of primary hypothyroid patients (Koulouri et al., 2011).

Growth hormone deficiency is present in a majority of CP patients and likely contributes to the metabolic derangements seen in this patient population. These metabolic effects are particularly important in adults, where GH replacement results in increased lean body mass and decreased body fat (Kronenberg and Williams, 2008). GH-deficiency has been shown to contribute to increased cardiovascular risk in hypopituitarism (Abs et al., 2006; Verhelst and $\mathrm{Abs}, 2009)$. The decision to replace $\mathrm{GH}$ in patients with a previous history of CP remains controversial although GH replacement does not appear to have any adverse effect on reoccurrence rates of CP in short term follow-up (Muller et al., 2010; Rohrer et al., 2010).

Hypogonadism and inadequately treated diabetes insipidus (DI) can also potentiate the effects of hypothalamic damage on excessive weight gain. Testosterone replacement, in hypogonadal men has been shown to have beneficial effects on body composition, blood pressure, and glucose homeostasis (Katznelson et al., 1996; Boyanov et al., 2003; Wittert et al., 2003). The effects of estrogen replacement on weight gain and body composition are more mixed and unclear, but premenopausal women who are hypogonadal should be physiologically replaced barring other contraindications (Norman et al., 2000). Inadequate control of DI can lead to excessive drinking of calories, poor sleep quality, and increased appetite (Beccuti and Pannain, 2011).

Altered carbohydrate and insulin dynamics have been shown to occur with CP and its treatment. While fasting glucose levels are generally no different from controls, CP patients have an exaggerated first and second phase insulin response to carbohydrate challenge (Lustig et al., 1999). Hyperinsulinism in hypothalamic damage is a result of both decreased inhibitory tone by sympathetic pathways and augmented vagal parasympathetic signaling to the pancreatic $\beta$-cell, and is not primarily a response to insulin resistance. Vagally mediated acetylcholine, acting through $\mathrm{M}_{3}$ muscarinic receptors, promotes depolarization of the $\beta$-cell through increased sodium influx, and mobilization of intracellular calcium stores through activation of the phospholipase $\mathrm{C}$ pathway (Miura et al., 1996). In addition, increased vagal activity stimulates release of the intestinal peptide glucagon-like peptide-1, itself a potentiator of insulin secretion (Rocca and Brubaker, 1999; Lustig, 2008). Increased insulin secretion in turn directs calories toward storage within the adipocyte.

Thus, the disruption of hypothalamic centers that occurs as a direct result of CP or its treatment creates a situation in which efferent drives to consume and store energy are disengaged from afferent signals that would otherwise dampen such drives. The obesity that results, driven by neural and biochemical stimuli, is often severe and intractable to therapy. While lifestyle changes such as caloric restriction and increased exercise should be encouraged, these interventions alone are often not successful, leaving patients frustrated with cravings, constant hunger, and lack of progress. Further, in addition to panhypopituitarism, HyOb patients are susceptible to the same metabolic derangements seen in other types of obesity such as diabetes, dyslipidemia, and heart disease (Srinivasan et al., 2004). For patients already facing significant challenges as a result of their primary disease, the negative impact of such comorbidities on quality of life adds insult to injury.

Unfortunately, in the last several years pharmacologic agents available for weight loss treatment have significantly declined, as the most effective agents (i.e., phen-fen, sibutramine) have been withdrawn from the market for unacceptable side-effect profiles. Small studies in CP of stimulants such as modafinil, methylphenidate, and dextroamphetamine have been shown to improve daytime sleepiness, affect, and alertness in HyOb (Mason et al., 2002; Muller et al., 2006), but none have proven truly effective at reversing the severe weight gain seen in this condition. Targeting the hyperinsulinism seen in HyOb, Lustig et al. (2006) demonstrated that octreotide could induce a modest decrease in $\operatorname{BMI}\left(0.79 \mathrm{~kg} / \mathrm{m}^{2}\right)$. A recent preliminary trial of diazoxide and metformin combined therapy demonstrated a slowing of weight gain with a stabilization of BMI over the 6-months of therapy (Hamilton et al., 2011). Taken as a whole, the efficacy of pharmacotherapy in treating $\mathrm{CP}-\mathrm{HyOb}$ is tepid at best. Because $\mathrm{CP}-\mathrm{HyOb}$ results from damage to the afferent target centers of the hypothalamus, agents targeting the efferent pathways to increase metabolic rate and/or thermogenesis may prove to be more effective (Bays, 2004). Newer agents targeting these efferent pathways are desperately needed.

\section{SURGICAL TREATMENT OF HyOb}

Given the limited choices and poor results of pharmacotherapy, combined with emerging data suggesting that gastrointestinal surgical procedures effect weight loss by altering the body's weight regulatory signaling pathways, several groups have looked to bariatric surgery as a viable option for producing sustained weight loss for patients with $\mathrm{CP}-\mathrm{HyOb}$. A range of procedures are available and are generally divided into three categories: restrictive, malabsorptive, and hybrid procedures. Restrictive procedures, such as gastric banding (GB) or vertical banded gastroplasty (VBG), aim to reduce stomach volume resulting in early satiety and smaller meal consumption. The natural course that nutrients follow is not altered, however. Pure malabsorptive procedures including 
jejunoileal and duodenal-jejunal bypass, as well as biliopancreatic diversion (BPD) involve the diversion of ingested food, bypassing one or more sections of intestine. The former two of these procedures have largely fallen out of favor secondary to associated nutritional deficits (Organ et al., 1984). A hybrid procedure, the Roux-en-Y gastric bypass (RYGB) has become the "gold standard" and the most commonly performed bariatric surgery for weight loss. It entails dividing the stomach to create a small gastric pouch which is anastomosed to a roux limb of jejunum. An enteroenterostomy is then made between the excluded biliopancreatic limb and the roux alimentary limb (Karra et al., 2010).

Bariatric surgery remains the most effective treatment for morbid obesity and is indicated for adult patients with a BMI $>40 \mathrm{~kg} / \mathrm{m}^{2}$ or a BMI of $>35 \mathrm{~kg} / \mathrm{m}^{2}$ and significant obesityrelated comorbidities (Pories et al., 1995). More conservative indications have generally been advocated for weight loss surgery in adolescent patients (see Discussion and Future Directions). An extensive body of research has shown that patients often show measurable improvement in metabolic parameters including glucose homeostasis in the early post-operative period, independent of weight loss. While the exact mechanisms of this phenomenon are still unclear, it appears that gastric bypass alters the secretion of gut hormones that favor improved metabolism and may also counteract certain elements of the orexigenic and energy conserving hypothalamic response to voluntary weight loss. Indeed, a number of studies over the last 30 years have shown that GLP-1, an incretin hormone secreted by enteroendocrine cells of the distal ileum, is increased following bariatric surgery. The evidence is especially consistent for bypass procedures, whereas restrictive procedures have been associated with no change or a decrease in GLP-1 levels (Sarson et al., 1981; Koopmans et al., 1984; Laferrere et al., 2008).

GLP-1 has been shown to have a number of positive effects on glucose metabolism including potentiating glucose-dependent insulin secretion, improving insulin sensitivity, and suppressing glucagon secretion. In addition, it has been shown to slow gastric emptying and promote early satiety. GLP-1 exerts these pleiotropic effect by acting on specific receptors located on pancreatic $\beta$-cells, peripheral vagal afferent fibers, as well as centrally located neurons (Baggio and Drucker, 2007). In addition, bariatric surgery has been shown to increase other anorexigenic hormones such as PYY and decrease orexigenic hormones such as ghrelin (Cummings et al., 2002b; le Roux et al., 2006). Human and animal studies appear to indicate that exposure of the distal gut to nutrient-rich, partially digested food results in increased secretion of hormones such as GLP-1 and PYY. This altered hormonal milieu accounts for the greater than $80 \%$ remission in diabetes following RYGB, often within days to weeks of surgery, and a combination of malabsorption, gastric restriction, and hormonal changes that accounts for the consistent and durable weight loss seen following such procedures (Buchwald et al., 2004; Karra et al., 2010).

Despite the large body of evidence demonstrating the benefits of bariatric surgery in treating exogenous obesity and its comorbidities, its role in the treatment of $\mathrm{HyOb}$ has yet to be defined. To date, the existing literature on bariatric surgery in $\mathrm{CP}-\mathrm{HyOb}$ is largely limited to case reports and series with short term follow-up. A PubMed search for "craniopharyngioma" and "bariatric surgery" results in four citations with a total of eight patients. Procedures performed include two RYGB, four laparoscopic adjustable band (LAGB), one distal gastric bypass, and one biliopancreatic derivation with duodenal switch.

In the first report of RYGB for CP-HyOb, we reported on an 18-year-old male who underwent a successful RYGB with anterior truncal vagotomy (due to the presumed importance of vagal efferents in CP-related hyperinsulinemia) for massive weight gain following the resection of a CP 3 years previous. At the time of $\mathrm{CP}$ diagnosis, his BMI was $25 \mathrm{~kg} / \mathrm{m}^{2}$. During the 2-years following CP resection, he developed hyperphagia and significant weight gain (70 kg/year) despite outpatient and inpatient dietary and physical activity interventions. Significant hyperinsulinism was noted and the patient was started on octreotide therapy with significant deceleration in weight gain but no weight loss. At the time of his bariatric surgery consultation, he had developed severe OSA, left ventricular hypertrophy, and hypertriglyceridemia. The post-operative course was significant for a $49-\mathrm{kg}$ weight loss over 2.5 years, although weight appeared to stabilize thereafter (BMI $\left.\sim 50 \mathrm{~kg} / \mathrm{m}^{2}\right)$. Further, serum triglycerides and left ventricular hypertrophy normalized. Hyperphagia decreased and food cravings (as measured by a Food Craving Inventory) diminished for all food types. Ten days following RYGB surgery, there was a fivefold decrease in fasting insulin, with normalization of fasting levels by 7 months. His post-prandial insulin excursion completely normalized by 14 months. As well, measurements of the orexigenic hormone ghrelin revealed a moderate decrease over the same time period.

In a different approach, Schultes et al. describe their approach to bypass surgery in a 29 -year-old male with childhood CP. Following $\mathrm{CP}$ resection 21 years previous, the patient had experienced continuous weight gain, developed type 2 diabetes, and OSA requiring continuous positive airway pressure therapy at night. At the time of $\mathrm{HyOb}$ surgical consultation, this patient was on hormone replacement for panhypopituitarism as well as metformin and nateglinide for diabetes treatment. To promote preoperative weight loss, he was started on $15 \mathrm{mg}$ sibutramine and enrolled in a rigorous supervised diet and exercise regimen which resulted in $9 \mathrm{~kg}$ weight loss over 9 months. Because bypass-induced hormonal alterations may exert their influence via hypothalamic mechanisms, it was felt that this patient, with complete hypothalamic atrophy, may not benefit. Therefore, a distal gastric bypass, producing a significantly shorter common channel of $80 \mathrm{~cm}$, was performed with the goal of inducing a strong malabsorption component. Following surgery, the patient experienced a precipitous weight loss, losing over $50 \mathrm{~kg}$ ( $\sim 30 \%$ of preoperative weight) over 18 months. In addition, the patient exhibited complete resolution of his diabetes and OSA and distinct reduction feelings of hunger and disinhibition on the three factor eating questionnaire (Schultes et al., 2009). The postoperative course was largely uneventful, although the patient did develop mild nutritional deficiencies despite standardized supplementation. These included anemia, deficiencies in vitamin D, B12, and zinc as well as hypoproteinemia.

In a series of four adolescent patients with childhood $\mathrm{CP}$ and obesity, Muller et al. found significant weight loss in all patients after LAGB. Patients participated in the German multicenter surveillance study on childhood CP termed "HIT-EndoKraniopharyngeom." The age of the patients ranged from 13 to 
24 years of age and BMI-SDS scores ranged from +7.3 to +13.9 . Following surgery, BMI-SDS scores improved on average by -0.7 per year of follow-up, with follow-up ranging from 1.5 to 4.5 years. Patients also reported significant changes in eating behavior, with reduced food cravings especially for sweets. Quality of life and functional capacity, measured by a standardized and validated scale, remained stable following surgery. Of the four patients, two experienced dislocation of the LAGB resulting in temporary weight gain and requiring laparoscopic revision. No other side-effects were reported (Muller et al., 2007).

Rottembourg et al. (2009) reported on two adolescents with post-CP-HyOb who underwent bariatric surgery as treatment for morbid obesity associated with significant comorbidities. The first was a 12-year-old female diagnosed with CP at age of 6 years. After gross total resection she developed panhypopituitarism and exhibited a rapid weight gain of $20 \mathrm{~kg}$ in the first 6 months. At the time of RYGB her BMI was $65 \mathrm{~kg} / \mathrm{m}^{2}$ and she had developed dyslipidemia, hepatosteatosis, frequent respiratory tract infections, and evidence of hypoventilation. Postoperatively, she demonstrated sustained weight loss over 4 years (BMI $43 \mathrm{~kg} / \mathrm{m}^{2}$ at last follow-up). In addition, dyslipidemia normalized, sleep patterns improved, and she had no further respiratory infections. She was subsequently diagnosed with fibromyalgia and symptomatic hyperuricemia, which were treated with regular analgesia and allopurinol. She also required ongoing treatment for depression. In addition, she developed a dumping-type syndrome (pallor, diaphoresis, and shakiness following meals) without associated hypoglycemia. The second patient was a 15-year-old male, diagnosed with $\mathrm{CP}$ at age of 4 years, also with panhypopituitarism and rapid weight gain following gross total resection. Comorbidities included dyslipidemia, hepatosteatosis, and hyperinsulinism. At the age of 14 years, a trial of octreotide led to no reduction of weight gain. At the time of bariatric surgery, his BMI was $42 \mathrm{~kg} / \mathrm{m}^{2}$. Given that the underlying cause of obesity was biological and would be present life-long, the surgeons involved felt that a diversionary surgical procedure would be a better option than LAGB. Following a BPD with duodenal switch, his BMI decreased to $32 \mathrm{~kg} / \mathrm{m}^{2}$ over the 2-year follow-up. The post-operative course was complicated by bradycardia requiring pacemaker placement, and stenosis of the distal surgical anastomosis requiring several laparoscopic repairs. Overall, both patients exhibited robust, sustained weight loss with resolution of metabolic comorbidities.

The efficacy of bariatric surgery for weight loss has also been examined in other $\mathrm{HyOb}$ patient populations. Scheimann et al. recently reported a retrospective critical analysis of bariatric procedures in PWS. PWS is a complex genetic disorder that results in marked hyperphagia and obesity felt to be secondary to hypothalamic dysfunction. The critical analysis revealed that a number of procedures, including BPD, RYGB, VBG, and endoscopic intragastric balloon placement have been used in this population. A review of 60 PWS patients highlighted the limited effectiveness and concerning safety profile of operations for weight loss in this unique population (Scheimann et al., 2008). In the short term, there appears to be some limited weight loss that is variable across different procedures. For RYGB, average weight loss was $4.2 \%$ for PWS patients after 6 months. Twelve month and 24 month follow-up revealed 6.5 and $2 \%$ weight loss, respectively.
This weight loss is far less than the $35 \%$ reduction in BMI we see 1 year after RYGB for adolescents who do not have PWS. Five year follow-up, while limited, showed only a $2.4 \%$ weight loss in PWS patients after RYGB $(n=9)$. Long term weight loss was worse with VBG, with PWS patients experiencing a $3.5 \%$ weight gain after 5 years $(n=2)$. Patients undergoing BPD had higher weight loss of $27.6 \%$ at 12 -months, but nearly half regained weight within $2-5$ years. In addition, the report highlights what appears to be a high post-operative complication rate, with $47 \%$ requiring surgical revision after RYGB and $27 \%$ experiencing acute gastric dilation (Scheimann et al., 2008).

Bariatric surgery has also been reported in an adolescent patient with BBS. Patients with BBS demonstrate hyperphagia and obesity which have been linked to disruption of primary cilia in POMC neurons in the hypothalamus and possibly to altered leptin receptor functioning. In this 16-year-old with a BMI of $53 \mathrm{~kg} / \mathrm{m}^{2}$, RYGB resulted in a 33\% reduction in BMI 3 years following surgery (Daskalakis et al., 2010). Improvement in hypertension and hyperuricemia was also observed.

Finally, as melanocortin 4 receptor (MC4R) variants represent the most common monogenetic form of HyOb in humans, it is relevant to assess the outcome of bariatric surgery in individuals with documented MC4R mutations. Surgical experience in this special group of $\mathrm{HyOb}$ patients is very limited. A group of investigators at the University of California San Francisco (UCSF) described surgical outcomes in an adolescent patient with a complete loss of function mutation at MC4R. This 18-year-old male presented with a preoperative weight of $166 \mathrm{~kg}$ and BMI of $54 \mathrm{~kg} / \mathrm{m}^{2}$ and underwent bilateral truncal vagotomy and laparoscopic adjustable GB. In this patient, the surgical intervention did not result in successful weight loss. Indeed, after an initial modest weight reduction of $12 \mathrm{~kg}$ over the first 4 months, the patient regained weight and by 1 year was $6.5 \mathrm{~kg}$ over his preoperative weight. Several features of the case however are relevant to interpretation of the outcome. First, the patient had moved away to college 4 months prior to the operation, and had in that time experienced a 66-kg weight gain. Also, the patient returned for only two band adjustments in the 1-year period of time, which is markedly less than the typically recommended post-operative adjustment schedule. Finally, the authors described an insatiable hunger 1 year after the operation, which was almost certainly a factor contributing to weight gain (Aslan et al., 2011b).

In a more recent publication from the same group at UCSF, the first report of an experience with gastric bypass in the setting of mutant MC4R contrasts with the results obtained after GB. Aslan et al. analyzed 1 year outcomes of four adults with heterozygous MC4R mutations in comparison to matched controls with normal MC4R gene sequences. Excess weight loss (EWL) in these four subjects was identical to the $60-70 \%$ EWL seen in matched controls. There was no mention of changes in post-operative appetite in these patients, nor any changes in metabolic features in this cohort (Aslan et al., 2011a).

\section{DISCUSSION AND FUTURE DIRECTIONS}

Hypothalamic obesity is observed in a high percentage of patients with $\mathrm{CP}$, resulting in significant comorbidities and negatively impacting quality of life. Unfortunately, few treatments have 
proven effective in this patient population. First line therapy for $\mathrm{HyOb}$ should include aggressive lifestyle modification including appropriate caloric intake and activity. Pituitary hormone deficiencies, if any, should be replaced and doses optimized. As mentioned previously, glucocorticoid replacement should be targeted at replacement doses $\left(8-10 \mathrm{mg} / \mathrm{m}^{2} /\right.$ day hydrocortisone equivalent) and patients should be given the lowest dose possible that is adequate to avoid symptoms of adrenal insufficiency. Thyroid replacement should generally target the fT4 at the upper third of the normal range and patients should be clinically and biochemically monitored for signs/symptoms of hyper- and hypothyroidism (Rose, 2010). The decision to replace GH should be made in consultation with the patient, family, and other team members such as their oncologist and neurosurgeon. If done, GH doses should be titrated to keep IGF-1 levels within the median range. Ideally, other medical treatments aimed specifically at ameliorating weight should be pursued through approved protocols at centers capable of collecting outcomes data on a sufficiently large number of patients so that risks and benefits of treatment can be more precisely defined. This is especially important with respect to bariatric surgery in this population.

Here, we have reviewed the current body of published research on bariatric surgery in $\mathrm{CP}-\mathrm{HyOb}$. We have also included several published reports of bariatric surgery in other populations of $\mathrm{HyOb}$, including PWS, BBS, and patients with MC4R mutations. While the limited scope of these reports makes comparison difficult, the experience in PWS patients demonstrates that all cases of $\mathrm{HyOb}$ should not be treated equally. Likely as a result of the multisystemic nature of their disorder, PWS patients have a significantly increased incidence of complications following bariatric surgery without the benefits of sustained weight loss. In addition, it appears that early dietary interventions are able to partially abrogate weight gain this population (Schmidt et al., 2008). Thus, the risk-benefit ratio of bariatric surgery in PWS does not appear to be favorable.

The initial reports of bariatric surgery in $\mathrm{CP}-\mathrm{HyOb}$ and patients with MC4Rappear more promising, but again, their limited scope makes it difficult to draw any substantial conclusions as to the long term safety and efficacy of these procedures in this population. The limited number of cases inhibits comparison among various procedures. For instance, how does RYGB compare to LAGB with regard to long term, sustained weight loss, or with regard to safety and side-effects? In addition, more work is needed to understand the hormonal alterations that occur in $\mathrm{CP}-$ $\mathrm{HyOb}$ following bariatric surgery. Are such alterations similar to those seen in diet-induced obesity? If not, why? If so, do CP-HyOb patients derive the same benefits given their underlying hypothalamic damage? If hyperinsulinism is an underlying factor in the development of $\mathrm{HyOb}$, will patients benefit or be harmed from increased levels of the insulin secretagogues such as GLP-1. Will potentiating insulin secretion place these patients at higher risk of hypoglycemia secondary to the mismatch of insulin secretion and carbohydrate absorption? These and other questions remain unanswered by the current body of research in this population and should be the subject of future work.

In addition, as $50 \%$ of patients diagnosed with CP are children, there are serious medical, psychological, and ethical concerns regarding bariatric surgery that must be considered in this population (Inge et al., 2004). Generally, adolescent candidates for bariatric surgery must meet more conservative patient selection criteria than are acceptable in adults. However, exact criteria are still of some debate. In 2008, the Endocrine Society, in conjunction with the Pediatric Endocrine Society, published a Clinical Practice Guideline on the Prevention and Treatment of Pediatric Obesity, wherein the task force recommended limiting bariatric surgery to adolescents with a BMI $\geq 50 \mathrm{~kg} / \mathrm{m}^{2}$ or a BMI $\geq 40 \mathrm{~kg} / \mathrm{m}^{2}$ with significant, severe comorbidities. In addition, the task force recommended that candidates have attained Tanner 4 or 5 pubertal development and near-final adult height, experienced continued weight gain despite following a formal program of lifestyle modification, and belong to a stable, medically competent family unit. The patient and family should understand that bariatric surgery is not a cure for obesity, but rather an adjunct to a continued commitment to lifestyle modifications in diet and activity. The surgery should be performed by an experienced surgeon in a medical center employing a team capable of long term followup and participating in a study of bariatric surgery outcomes. These recommendations largely agree with guidelines previously published and advocate the priority of avoiding unforeseen complications associated with life-long exposure to anatomical and functional alterations above the value of weight loss and amelioration of obesity-related complications provided by bariatric surgery (August et al., 2008).

More recently, Pratt et al. (2009) suggest that adolescents with a $\mathrm{BMI} \geq 35 \mathrm{~kg} / \mathrm{m}^{2}$ and serious comorbidities including Type 2 diabetes, moderate to severe OSA, and/or pseudotumor cerebri or those with $\mathrm{BMI} \geq 40 \mathrm{~kg} / \mathrm{m}^{2}$ with less serious comorbid conditions such as hypertension, dyslipidemia, gastroesophageal reflux disease, and/or psychosocial stress should be considered as candidates for bariatric surgery. While concurring with the other physical, lifestyle, and psychosocial criteria previously published, they use several lines of evidence to defend the lower BMI criteria. First, they cite data to indicate that patient safety and weight loss outcomes for extremely obese adolescents who undergo bariatric surgery are comparable to, or better than, those seen in adults. Second, even with the lower BMI criteria of $35 \mathrm{~kg} / \mathrm{m}^{2}$, candidates under the age of 18 would still be above the 99th BMI percentile and be at substantially increased risk for short and long term medical comorbidities. Third, they stress that selection for bariatric surgery during adolescence should be closely linked to obesityrelated comorbidities. The less severe comorbidities and/or fewer risk factors for long term disease, the higher the BMI cut point should be before considering bariatric surgery. Finally, some have suggested that because younger patients will generally have fewer advanced comorbidities, early bariatric surgery may decrease the risk of future perioperative mortality, assuming the needed surgery is delayed until adulthood (Garcia and DeMaria, 2006).

Importantly, none of the guidelines for bariatric surgery directly addresses the use of bariatric surgery in $\mathrm{HyOb}$ generally or $\mathrm{CP}-\mathrm{HyOb}$ in particular. In general, we believe that most criteria from the published guidelines can be applied to the $\mathrm{HyOb}$ patients, especially in adults. Whether one or more of the published criteria should be modified in the context of children and adolescents is subject to ongoing debate. Given what is known 
about the natural history of $\mathrm{HyOb}$, its resistance to diet and lifestyle modification, and the extreme and progressive weight gain involved, some may consider bariatric surgery appropriate at ages currently considered too young in patients with exogenous obesity. However, in general, the younger the patient the more compelling and serious the comorbidities must be to justify surgical intervention. Because of the need for life-long medical support, optimal care of $\mathrm{HyOb}$ patients will be best met in the setting of tertiary care centers where they can receive treatment in a coordinated, multidisciplinary fashion. Team members should include the primary care physician and as needed subspecialists in neurosurgery, neurology, oncology, endocrinology, bariatric surgery, and mental health. Ideally, ancillary support by nutrition, physical therapy, nursing, and social work should also be available. Patients and families choosing to undergo bariatric surgery should be properly informed regarding specific risks and benefits associated with surgical weight loss and age appropriate consent or assent obtained. To facilitate needed research in this area, patients should be encouraged to enroll in available databases and research protocols.

These early reports of outcome of surgical weight loss treatment of $\mathrm{HyOb}$ are limited in scope and number, but give us a glimpse of the possible role of surgery in treatment of these conditions. They also make evident the need for more robust, controlled, prospective studies with long term follow-up in order to better

\section{REFERENCES}

Abeloff, M. D. (2008). Abeloff's Clinical Oncology. Philadelphia: Churchill Livingstone/Elsevier.

Abs, R., Feldt-Rasmussen, U., Mattsson, A. F., Monson, J. P., Bengtsson, B. A., Goth, M. I., Wilton, P., and Koltowska-Haggstrom, M. (2006). Determinants of cardiovascular risk in 2589 hypopituitary GH-deficient adults - a KIMS database analysis. Eur. J. Endocrinol. 155, 79-90.

Ahmet, A., Blaser, S., Stephens, D., Guger, S., Rutkas, J. T., and Hamilton, J. (2006). Weight gain in craniopharyngioma - a model for hypothalamic obesity. J. Pediatr. Endocrinol. Metab. 19, 121-127.

Aslan, I. R., Campos, G. M., Calton, M. A., Evans, D. S., Merriman, R. B., and Vaisse, C. (2011a). Weight loss after Roux-en-Y gastric bypass in obese patients heterozygous for MC4R mutations. Obes. Surg. 21, 930-934.

Aslan, I. R., Ranadive, S. A., Ersoy, B. A., Rogers, S. J., Lustig, R. H., and Vaisse, C. (2011b). Bariatric surgery in a patient with complete MC4R deficiency. Int. J. Obes. (Lond.) 35, 457-461.

August, G. P., Caprio, S., Fennoy, I., Freemark, M., Kaufman, F. R., Lustig, R. H., Silverstein, J. H., Speiser, P. W., Styne, D. M., and Montori, V. M. (2008). Prevention and treatment of pediatric obesity: an endocrine

define the role of medical as well as surgical therapies in the treatment of HyOb. In order to ultimately understand the outcome of surgical therapy for $\mathrm{HyOb}$, sufficiently long follow-up of sufficient numbers of similar patients who undergo surgery as well as non-surgical controls will be required. Non-human surgical models might also in the future permit a better understanding of the mechanisms of obesity, and the importance of tailoring specific operative elements to each unique population.

Research in this important area is hampered by the difficulty of assembling a sufficiently large cohort of $\mathrm{CP}-\mathrm{HyOb}$ patients. Given the relative rarity of the condition, it would take a single institution many years to put together a study large enough to reach valid, persuasive conclusions regarding the treatment of $\mathrm{HyOb}-$ surgical or otherwise. In order to increase public awareness of $\mathrm{HyOb}$, facilitate future research and ultimately improve the management of $\mathrm{HyOb}$, the International Registry for $\mathrm{HyOb}$ Disorders (www.IRHOD.org) has been established. The web-based interface will permit both healthcare providers and patient/families to easily enter basic information regarding their $\mathrm{HyOb}$ case. The systematic accumulation of a large world-wide cohort of patients with $\mathrm{HyOb}$ will facilitate recognition of individuals eligible for participation in studies of $\mathrm{HyOb}$ and its treatment. This registry, therefore, has potential to fill many of the numerous knowledge gaps around pathogenesis, coexisting disease, and treatment outcomes for this debilitating form of obesity.

Bougneres, P., Lebouc, Y., Froguel, P., and Guy-Grand, B. (1998). A mutation in the human leptin receptor gene causes obesity and pituitary dysfunction. Nature 392, 398-401.

Coutant, R., Maurey, H., Rouleau, S. Mathieu, E., Mercier, P., Limal, J. M., and Le Bouil, A. (2003). Defect in epinephrine production in children with craniopharyngioma: functional or organic origin? J. Clin. Endocrinol. Metab. 88, 5969-5975.

Cummings, D. E., Clement, K., Purnell, J. Q., Vaisse, C., Foster, K. E., Frayo, R. S., Schwartz, M. W., Basdevant, A., and Weigle, D. S. (2002a). Elevated plasma ghrelin levels in Prader Willi syndrome. Nat. Med. 8, 643-644.

Cummings, D. E., Weigle, D. S., Frayo, R. S., Breen, P. A., Ma, M. K., Dellinger, E. P., and Purnell, J. Q. (2002b). Plasma ghrelin levels after diet-induced weight loss or gastric bypass surgery. N. Engl. J. Med. 346, 1623-1630.

Daskalakis, M., Till, H., Kiess, W., and Weiner, R. A. (2010). Roux-en$\mathrm{Y}$ gastric bypass in an adolescent patient with Bardet-Biedl syndrome, a monogenic obesity disorder. Obes. Surg. 20, 121-125.

de Vile, C. J., Grant, D. B., Hayward, R. D., Kendall, B. E., Neville, B. G., and Stanhope, R. (1996). Obesity in childhood craniopharyngioma: relation to post-operative hypothalamic damage shown by magnetic resonance imaging. J. Clin. Endocrinol. Metab. 81, 2734-2737.

Debono, M., Ross, R. J., and NewellPrice, J. (2009). Inadequacies of glucocorticoid replacement and improvements by physiological circadian therapy. Eur. J. Endocrinol. 160, 719-729.

DelParigi, A., Tschop, M., Heiman, M. L., Salbe, A. D., Vozarova, B., Sell, S. M., Bunt, J. C., and Tataranni, P. A. (2002). High circulating ghrelin: a potential cause for hyperphagia and obesity in Prader-Willi syndrome. J. Clin. Endocrinol. Metab. 87, 5461-5464.

Eiholzer, U., Blum, W. F., and Molinari, L. (1999). Body fat determined by skinfold measurements is elevated despite underweight in infants with Prader-LabhartWilli syndrome. J. Pediatr. 134, 222-225.

Esteban, N. V., Loughlin, T., Yergey, A. L., Zawadzki, J. K., Booth, J. D., Winterer, J. C., and Loriaux, D. L. (1991). Daily cortisol production rate in man determined by stable isotope dilution/mass spectrometry. J. Clin. Endocrinol. Metab. 72, 39-45.

Eyal, O., Sundararajan, S., Inge, T. H., and Rose, S. R. (2006). Obesity in patients with craniopharyngioma. Endocrinologist 16, 286-293. 
Filipsson, H., Monson, J. P., KoltowskaHaggstrom, M., Mattsson, A., and Johannsson, G. (2006). The impact of glucocorticoid replacement regimens on metabolic outcome and comorbidity in hypopituitary patients. J. Clin. Endocrinol. Metab. 91, 3954-3961.

Garcia, V. F., and DeMaria, E. J. (2006). Adolescent bariatric surgery: treatment delayed, treatment denied, a crisis invited. Obes. Surg. 16, 1-4.

Goldstone, A. P., Holland, A. J., Hauffa, B. P., Hokken-Koelega, A. C., and Tauber, M. (2008). Recommendations for the diagnosis and management of Prader-Willi syndrome. J. Clin. Endocrinol. Metab. 93, 4183-4197.

Guo, D. F., and Rahmouni, K. (2011). Molecular basis of the obesity associated with Bardet-Biedl syndrome. Trends Endocrinol. Metab. 22, 286-293.

Hamilton, J. K., Conwell, L. S., Syme, C., Ahmet, A., Jeffery, A., and Daneman, D. (2011). Hypothalamic obesity following craniopharyngioma surgery: results of a pilot trial of combined diazoxide and metformin therapy. Int. J. Pediatr. Endocrinol. 2011, 417949.

Harwood-Nash, D. C. (1994). Neuroimaging of childhood craniopharyngioma. Pediatr. Neurosurg. 21(Suppl. 1), 2-10.

Harz, K. J., Muller, H. L., Waldeck, E., Pudel, V., and Roth, C. (2003). Obesity in patients with craniopharyngioma: assessment of food intake and movement counts indicating physical activity. J. Clin. Endocrinol. Metab. 88, 5227-5231.

Hetherington, A. W., and Ranson, S. W. (1940). Hypothalamic lesions and adiposity in the rat. Anat. Rec. 78, 149-172.

Hochberg, I., and Hochberg, Z. (2010). Expanding the definition of hypothalamic obesity. Obes. Rev. 11, 709-721.

Holmer, H., Pozarek, G., Wirfalt, E., Popovic, V., Ekman, B., Bjork, J., and Erfurth, E. M. (2010). Reduced energy expenditure and impaired feeding-related signals but not high energy intake reinforces hypothalamic obesity in adults with childhood onset craniopharyngioma. J. Clin. Endocrinol. Metab. 95, 5395-5402.

Inge, T. H., Krebs, N. F., Garcia, V. F., Skelton, J. A., Guice, K. S., Strauss, R. S., Albanese, C. T., Brandt, M. L., Hammer, L. D., Harmon, C. M., Kane, T. D., Klish, W. J., Oldham, K. T., Rudolph, C. D., Helmrath, M. A., Donovan, E., and Daniels, S. R. (2004). Bariatric surgery for severely overweight adolescents: concerns and recommendations. Pediatrics 114, 217-223.

Inge, T. H., Pfluger, P., Zeller, M., Rose, S. R., Burget, L., Sundararajan, S., Daniels, S. R., and Tschop, M. H. (2007). Gastric bypass surgery for treatment of hypothalamic obesity after craniopharyngioma therapy. Nat. Clin. Pract. Endocrinol. Metab. 3, 606-609.

Karavitaki, N., Brufani, C., Warner, J. T., Adams, C. B., Richards, P., Ansorge, O., Shine, B., Turner, H. E., and Wass, J. A. (2005). Craniopharyngiomas in children and adults: systematic analysis of 121 cases with long-term follow-up. Clin. Endocrinol. (Oxf.) 62, 397-409.

Karavitaki, N., Cudlip, S., Adams, C. B., and Wass, J. A. (2006). Craniopharyngiomas. Endocr. Rev. 27, 371-397.

Karra, E., Yousseif, A., and Batterham, R. L. (2010). Mechanisms facilitating weight loss and resolution of type 2 diabetes following bariatric surgery. Trends Endocrinol. Metab. 21, 337-344.

Katznelson, L., Finkelstein, J. S., Schoenfeld, D. A., Rosenthal, D. I., Anderson, E. J., and Klibanski, A. (1996). Increase in bone density and lean body mass during testosterone administration in men with acquired hypogonadism. J. Clin. Endocrinol. Metab. 81, 4358-4365.

Kerrigan, J. R., Veldhuis, J. D., Leyo, S. A., Iranmanesh, A., and Rogol, A. D. (1993). Estimation of daily cortisol production and clearance rates in normal pubertal males by deconvolution analysis. J. Clin. Endocrinol. Metab. 76, 1505-1510.

Koopmans, H. S., Ferri, G. L., Sarson, D. L., Polak, J. M., and Bloom, S. R. (1984). The effects of ileal transposition and jejunoileal bypass on food intake and GI hormone levels in rats. Physiol. Behav. 33, 601-609.

Koulouri, O., Auldin, M. A., Agarwal, R., Kieffer, V., Robertson, C., Falconer Smith, J., Levy, M. J., and Howlett, T. A. (2011). Diagnosis and treatment of hypothyroidism in TSH deficiency compared to primary thyroid disease: pituitary patients are at risk of under-replacement with levothyroxine. Clin. Endocrinol. (Oxf.) 74, 744-749.

Kronenberg, H., and Williams, R. H. (2008). Williams Textbook of Endocrinology. Philadelphia: Saunders/Elsevier.

Laferrere, B., Teixeira, J., Mcginty, J., Tran, H., Egger, J. R., Colarusso, A., Kovack, B., Bawa, B., Koshy, N., Lee, H., Yapp, K., and Olivan, B. (2008).
Effect of weight loss by gastric bypass surgery versus hypocaloric diet on glucose and incretin levels in patients with type 2 diabetes. J. Clin. Endocrinol. Metab. 93, 2479-2485.

le Roux, C. W., Aylwin, S. J., Batterham, R. L., Borg, C. M., Coyle, F., Prasad, V., Shurey, S., Ghatei, M. A., Patel, A. G., and Bloom, S. R. (2006). Gut hormone profiles following bariatric surgery favor an anorectic state, facilitate weight loss, and improve metabolic parameters. Ann. Surg. 243, 108-114.

Linder, B. L., Esteban, N. V., Yergey, A. L., Winterer, J. C., Loriaux, D. L., and Cassorla, F. (1990). Cortisol production rate in childhood and adolescence. J. Pediatr. 117, 892-896.

Lubrano-Berthelier, C., Dubern, B. Lacorte, J. M., Picard, F., Shapiro, A., Zhang, S., Bertrais, S., Hercberg, S., Basdevant, A., Clement, K., and Vaisse, C. (2006). Melanocortin 4 receptor mutations in a large cohort of severely obese adults: prevalence, functional classification, genotypephenotype relationship, and lack of association with binge eating. J. Clin. Endocrinol. Metab. 91, 1811-1818.

Lustig, R. H. (2008). Hypothalamic obesity: causes, consequences, treatment. Pediatr. Endocrinol. Rev. 6, 220-227.

Lustig, R. H., Greenway, F., VelasquezMieyer, P., Heimburger, D., Schumacher, D., Smith, D., Smith, W., Soler, N., Warsi, G., Berg, W., Maloney, J., Benedetto, J., Zhu, W., and Hohneker, J. (2006). A multicenter, randomized, double-blind, placebo-controlled, dose-finding trial of a long-acting formulation of octreotide in promoting weight loss in obese adults with insulin hypersecretion. Int. J. Obes. (Lond.) 30, 331-341.

Lustig, R. H., Rose, S. R., Burghen, G. A., Velasquez-Mieyer, P., Broome, D. C., Smith, K., Li, H., Hudson, M. M., Heideman, R. L., and Kun, L. E. (1999). Hypothalamic obesity caused by cranial insult in children: altered glucose and insulin dynamics and reversal by a somatostatin agonist. J. Pediatr. 135, 162-168.

Mason, P. W., Krawiecki, N., and Meacham, L. R. (2002). The use of dextroamphetamine to treat obesity and hyperphagia in children treated for craniopharyngioma. Arch. Pediatr. Adolesc. Med. 156, 887-892.

Miura, Y., Gilon, P., and Henquin, J. C. (1996). Muscarinic stimulation increases $\mathrm{Na}+$ entry in pancreatic B-cells by a mechanism other than the emptying of intracellular $\mathrm{Ca} 2+$ pools. Biochem. Biophys. Res. Commun. 224, 67-73.

Mortini, P., Losa, M., Pozzobon, G., Barzaghi, R., Riva, M., Acerno, S., Angius, D., Weber, G., Chiumello, G., and Giovanelli, M. (2011). Neurosurgical treatment of craniopharyngioma in adults and children: early and long-term results in a large case series. J. Neurosurg. 114, 1350-1359.

Muller, H. L. (2008). Childhood craniopharyngioma. Recent advances in diagnosis, treatment and follow-up. Horm. Res. 69, 193-202.

Muller, H. L., Bruhnken, G., Emser, A., Faldum, A., Etavard-Gorris, N., Gebhardt, U., Kolb, R., and Sorensen, N. (2005). Longitudinal study on quality of life in 102 survivors of childhood craniopharyngioma. Childs Nerv. Syst. 21, 975-980.

Muller, H. L., Bueb, K., Bartels, U., Roth, C., Harz, K., Graf, N., Korinthenberg, R., Bettendorf, M., Kuhl, J., Gutjahr, P., Sorensen, N., and Calaminus, G. (2001). Obesity after childhood craniopharyngioma-German multicenter study on pre-operative risk factors and quality of life. Klin. Padiatr. 213, 244-249.

Muller, H. L., Emser, A., Faldum, A., Bruhnken, G., Etavard-Gorris, N., Gebhardt, U., Oeverink, R., Kolb, R., and Sorensen, N. (2004). Longitudinal study on growth and body mass index before and after diagnosis of childhood craniopharyngioma. J. Clin. Endocrinol. Metab. 89, 3298-3305.

Muller, H. L., Gebhardt, U., Schroder, S., Pohl, F., Kortmann, R. D., Faldum, A., Zwiener, I., Warmuth-Metz, M., Pietsch, T., Calaminus, G., Kolb, R., Wiegand, C., and Sorensen, N. (2010). Analyses of treatment variables for patients with childhood craniopharyngioma - results of the multicenter prospective trial KRANIOPHARYNGEOM 2000 after three years of follow-up. Horm. Res. Paediatr. 73, 175-180.

Muller, H. L., Gebhardt, U., Wessel, V., Schroder, S., Kolb, R., Sorensen, N. Maroske, J., and Hanisch, E. (2007). First experiences with laparoscopic adjustable gastric banding (LAGB) in the treatment of patients with childhood craniopharyngioma and morbid obesity. Klin. Padiatr. 219, 323-325.

Muller, H. L., Handwerker, G., Wollny, B., Faldum, A., and Sorensen, N. (2002). Melatonin secretion and increased daytime sleepiness in childhood craniopharyngioma patients. J. Clin. Endocrinol. Metab. 87, 3993-3996. 
Muller, H. L., Muller-Stover, S., Gebhardt, U., Kolb, R., Sorensen, N., and Handwerker, G. (2006). Secondary narcolepsy may be a causative factor of increased daytime sleepiness in obese childhood craniopharyngioma patients. J. Pediatr. Endocrinol. Metab. 19(Suppl. 1), 423-429.

Norman, R. J., Flight, I. H., and Rees, M. C. (2000). Oestrogen and progestogen hormone replacement therapy for peri-menopausal and post-menopausal women: weight and body fat distribution. Cochrane Database Syst. Rev. 2, CD001018.

Organ, C. H. Jr., Kessler, E., and Lane, M. (1984). Long-term results of jejunoileal bypass in the young. Am. Surg. 50, 589-593.

Pories, W. J., Swanson, M. S., Macdonald, K. G., Long, S. B., Morris, P. G., Brown, B. M., Barakat, H. A., deRamon, R. A., Israel, G., Dolezal, J. M., and Dohm, L. (1995). Who would have thought it? An operation proves to be the most effective therapy for adult-onset diabetes mellitus. Ann. Surg. 222, 339-350; discussion 350-332.

Pratt, J. S., Lenders, C. M., Dionne, E. A., Hoppin, A. G., Hsu, G. L., Inge, T. H., Lawlor, D. F., Marino, M. F., Meyers, A. F., Rosenblum, J. L., and Sanchez, V. M. (2009). Best practice updates for pediatric/adolescent weight loss surgery. Obesity (Silver Spring) 17, 901-910.

Rocca, A. S., and Brubaker, P. L. (1999). Role of the vagus nerve in mediating proximal nutrient-induced glucagon-like peptide-1 secretion. Endocrinology 140, 1687-1694.

Rohrer, T. R., Langer, T., Grabenbauer, G. G., Buchfelder, M., Glowatzki, M., and Dorr, H. G. (2010). Growth hormone therapy and the risk of tumor recurrence after brain tumor treatment in children. J. Pediatr. Endocrinol. Metab. 23, 935-942.

Rose, S. R. (2010). Improved diagnosis of mild hypothyroidism using time-of-day normal ranges for thyrotropin. J. Pediatr. 157, 662-667.

Roth, C., Wilken, B., Hanefeld, F., Schroter, W., and Leonhardt, U. (1998). Hyperphagia in children with craniopharyngioma is associated with hyperleptinaemia and a failure in the downregulation of appetite. Eur. J. Endocrinol. 138, 89-91.

Roth, C. L., Gebhardt, U., and Muller, H. L. (2011). Appetite-regulating hormone changes in patients with craniopharyngioma. Obesity (Silver Spring) 19, 36-42.

Roth, C. L., Hunneman, D. H., Gebhardt, U., Stoffel-Wagner, B., Reinehr, T., and Muller, H. L. (2007). Reduced sympathetic metabolites in urine of obese patients with craniopharyngioma. Pediatr. Res. 61, 496-501.

Rottembourg, D., O'gorman, C. S., Urbach, S., Garneau, P. Y., Langer, J. C., Van Vliet, G., Hamilton, J., and Huot, C. (2009). Outcome after bariatric surgery in two adolescents with hypothalamic obesity following treatment of craniopharyngioma. J. Pediatr. Endocrinol. Metab. 22, 867-872.

Sarson, D. L., Scopinaro, N., and Bloom, S. R. (1981). Gut hormone changes after jejunoileal (JIB) or biliopancreatic (BPB) bypass surgery for morbid obesity. Int. J. Obes. 5, 471-480.

Savastano, D. M., Tanofsky-Kraff, M., Han, J. C., Ning, C., Sorg, R. A., Roza, C. A., Wolkoff, L. E., Anandalingam, K., Jefferson-George, K. S., Figueroa, R. E., Sanford, E. L., Brady, S., Kozlosky, M., Schoeller, D. A., and Yanovski, J. A. (2009). Energy intake and energy expenditure among children with polymorphisms of the melanocortin3 receptor. Am. J. Clin. Nutr. 90, 912-920.

Scheimann, A. O., Butler, M. G., Gourash, L., Cuffari, C., and Klish, W. (2008). Critical analysis of bariatric procedures in Prader-Willi syndrome. J. Pediatr. Gastroenterol. Nutr. 46, 80-83.
Schmidt, H., Pozza, S. B., Bonfig, W., Schwarz, H. P., and Dokoupil, K. (2008). Successful early dietary intervention avoids obesity in patients with Prader-Will syndrome: a ten-year follow-up. J. Pediatr. Endocrinol. Metab. 21, 651-655.

Schofl, C., Schleth, A., Berger, D. Terkamp, C., Von Zur Muhlen, A., and Brabant, G. (2002). Sympathoadrenal counterregulation in patients with hypothalamic craniopharyngioma. J. Clin. Endocrinol. Metab. 87, 624-629.

Schultes, B., Ernst, B., Schmid, F., and Thurnheer, M. (2009). Distal gastric bypass surgery for the treatment of hypothalamic obesity after childhood craniopharyngioma. Eur. J. Endocrinol. 161, 201-206.

Schwartz, M. W., Woods, S. C., Porte, D. Jr., Seeley, R. J., and Baskin, D. G. (2000). Central nervous system control of food intake. Nature 404 661-671.

Seo, S., Guo, D. F., Bugge, K., Morgan, D. A., Rahmouni, K., and Sheffield, V. C. (2009). Requirement of BardetBiedl syndrome proteins for leptin receptor signaling. Hum. Mol. Genet. $18,1323-1331$.

Skorzewska, A., Lal, S., Waserman, J. and Guyda, H. (1989). Abnormal food-seeking behavior after surgery for craniopharyngioma. Neuropsychobiology 21, 17-20.

Slawik, M., Klawitter, B., Meiser, E. Schories, M., Zwermann, O., Borm, K., Peper, M., Lubrich, B., Hug, M. J., Nauck, M., Olschewski, M. Beuschlein, F., and Reincke, M. (2007). Thyroid hormone replacement for central hypothyroidism: a randomized controlled trial comparing two doses of thyroxine (T4) with a combination of $\mathrm{T} 4$ and triiodothyronine. J. Clin. Endocrinol. Metab. 92, 4115-4122.

Sorva, R. (1988). Children with craniopharyngioma. Early growth failure and rapid postoperative weight gain. Acta Paediatr. Scand. 77, 587-592.
Srinivasan, S., Ogle, G. D., Garnett, S. P., Briody, J. N., Lee, J. W., and Cowell, C. T. (2004). Features of the metabolic syndrome after childhood craniopharyngioma. J. Clin. Endocrinol. Metab. 89, 81-86.

Verhelst, J., and Abs, R. (2009). Cardiovascular risk factors in hypopituitary GH-deficient adults. Eur. J. Endocrinol. 161(Suppl. 1), S41-S49.

Winkfield, K. M., Tsai, H. K., Yao, X., Larson, E., Neuberg, D., Pomeroy, S. L., Ullrich, N. J., Cohen, L. E., Kieran, M. W., Scott, R. M., Goumnerova, L. C., and Marcus, K. J. (2011) Long-term clinical outcomes following treatment of childhood craniopharyngioma. Pediatr. Blood Cancer 56, 1120-1126.

Wittert, G. A., Chapman, I. M., Haren, M. T., Mackintosh, S., Coates, P., and Morley, J. E. (2003). Oral testosterone supplementation increases muscle and decreases fat mass in healthy elderly males with lownormal gonadal status. J. Gerontol. A Biol. Sci. Med. Sci. 58, 618-625.

Conflict of Interest Statement: The authors declare that the research was conducted in the absence of any commercial or financial relationships that could be construed as a potential conflict of interest.

Received: 27 October 2011; accepted: 30 January 2012; published online: 14 February 2012.

Citation: Bingham NC, Rose SR and Inge TH (2012) Bariatric surgery in hypothalamic obesity. Front. Endocrin. 3:23. doi: 10.3389/fendo.2012.00023

This article was submitted to Frontiers in Pituitary Endocrinology, a specialty of Frontiers in Endocrinology.

Copyright (c) 2012 Bingham, Rose and Inge. This is an open-access article distributed under the terms of the Creative Commons Attribution Non Commercial License, which permits noncommercial use, distribution, and reproduction in other forums, provided the original authors and source are credited. 